Revista do CESP, Belo Horizonte, v.35, n.54, p. 67-74, 2015

\title{
Memória de Ruy Cinatti: uma entrevista com Peter Stilwell ${ }^{1,2}$
}

\section{Memory of Ruy Cinatti: an interview with Peter Stilwell}

Duarte Drumond Braga

Universidade de São Paulo - FAPESP

duartedbraga@gmail.com

Recebido em 27 de dezembro de 2015

Aprovado em 8 de janeiro de 2016

Duarte Drumond Braga - O seu encontro com Cinatti deu-se por via dos versos ou da pessoa?

Peter Stilwell - Foi por via da pessoa. O Cinatti, quando voltou a primeira vez de Timor, em 1947, acabou por ficar em casa dos meus pais. Ele esteve então em Portugal até 1951, altura em que voltou para Timor. O pai proibiu-o de ficar em casa da avó, como era seu hábito antes de ir para Timor em 1946, e o Ruy viu-se obrigado a alojar-se em casa de amigos. Em 1951, eu teria 4-5 anos e já tenho memória dele nessa altura. Era uma espécie de irmão mais velho, a brincar comigo e a correr pelos corredores. Noutro regresso de Timor, ficou connosco uns dias na casa em Sintra em que estávamos a passar o verão. Uma manhã, quando tomávamos o pequeno-almoço na cozinha, apareceu com o

\footnotetext{
${ }^{1}$ Professor Associado da Faculdade de Teologia da Universidade Católica Portuguesa, onde lecciona desde 1976, é atualmente reitor da Universidade de São José, em Macau (China). Doutorado com uma tese em Teologia sobre Ruy Cinatti, publicou em 1995 A condição humana em Ruy Cinatti, trabalho baseado na sua tese que ganhou Prémio Eça de Queiroz de ensaio. Editor e especialista na obra do poeta.

${ }^{2}$ Texto oriundo de pesquisa da Fundação de Amparo à Pesquisa do Estado de São Paulo (número do processo 2014/00829-8)
} 
lençol da cama a cobri-lo da cabeça aos pés, a fazer de fantasma. Foi tão inesperado num adulto que nos divertimos imenso. Mais tarde, em 1973, quando fui ordenado, fez questão de me oferecer um pequeno elefante maconde acerca do qual escreveu depois um poema a lembrar aquelas corridas pelos corredores atrás do meu elefante de pano. E a partir daí, encontrávamo-nos regularmente. Aparecia para a missa das 9, na Igreja de Santos-o-Velho, que eu celebrava, depois tomávamos um café e ele seguia para o seu emprego no Museu de Etnologia.

DDB - Mas antes ele está na Junta de Investigações do Ultramar...

PS - Sim, o Ruy foi investigador da Junta desde 1957. A esse título, foi primeiro para a Universidade de Londres e depois para Oxford frequentar uma pós-graduação em antropologia cultural. Mas, em Oxford, fizeramlhe uma avaliação e concluíram que devia passar diretamente para o doutoramento. Um daqueles casos raros. Infelizmente, perdeu-se o rastro da tese que preparou ao longo de dez anos mas nunca chegou a defender.

\section{DDB - ... que era precisamente sobre Timor.}

PS - Exatamente.A razão porque passou da agronomia, ou melhor da silvicultura, para a antropologia foi por ter chegado à conclusão, como secretário da agricultura em Timor de 1951 a 1956, que não era possível levar por diante um projeto de desenvolvimento agrícola sustentável sem ter em conta a cultura nativa dos timorenses. De início, Cinatti defendia ativa e afetivamente a natureza de Timor - o que na sua poesia se reflete. Ela encarnava a sua imagem das "ilhas do Mar do Sul". Daí a sua tristeza ao vê-la desrespeitada. Colonos portugueses chegavam, compravam terras e desbastavam-nas para produzir café ou outros produtos, segundo as modernas técnicas do Ocidente e os interesses do mercado. Mas as escarpas de Timor são íngremes e quando vinham as chuvas tudo ia, literalmente, por água abaixo. Isso contrastava com a sabedoria milenar no modo como as populações nativas atribuíam valor sagrado a certos bosques, considerados intocáveis.Graças a esse respeito, o terreno aí não deslizava. Dá-se então uma mudança na atitude de Cinatti. Se antes o encantavam as paisagens e os timorenses não passavam de "vultos" na sua escrita, à medida que descobre a harmonia entre cultura local e natureza, os timorenses tornam-se uma presença de carne e osso na sua obra, recolhe os seus mitos e até procura traduzir-lhe a poesia tradicional. 
Dois juramentos de sangue estão na linha dessa evolução e ligam-no para sempre à população timorense.

DDB - E o interesse por Timor é antigo, não é?

PS - Sim, o Ruy herda do avô o fascínio pelo Oriente. Conta nos seus diários que, ainda em jovem, gostava de estender um mapa e traçar nele viagens. E essas viagens eram para a África, para o Oriente, e para as ilhas dos mares do sul. Quando chegou a Timor, em meados de 1946, encantouse ao reencontrar esse sonho da juventude, entretanto perdidos. A Guerra Civil em Espanha e a segunda Guerra Mundial, assim como a influência da grande literatura e poesia ocidental da primeira metade do século vinte, tinham-lhe alterado os horizontes culturais. Era urgente participar na transformação da cultura europeia, que havia de renascer após o aparente colapso civilizacional das guerras. Mas, quando chega a Timor, em 1946, reencontra-se com o sonho de juventude, a exuberância das paisagens, a nobreza e vida simples de populações perante a destruição deixada pelos japoneses ao abandonar o território. Mas só muito mais tarde irá estabelecer pactos de sangue com dois liurais. Foi em 1962. Na altura fez também filmagens importantes das práticas tradicionais dos timorenses, que estão guardadas no Museu de Etnologia, em Lisboa. Levou com ele um profissional para as filmagens, mas era ele quem dirigia o trabalho. Aliás, temos provas que era um excelente fotógrafo.

DDB - Podemos dizer que Cinatti quer dar um rosto a Timor, de tal maneira que o nome dele se confunde com Timor. Quer falar-nos um pouco sobre isso?

PS - Numa entrevista de 1972, Cinatti diz que em Timor tudo para ele era poesia e que, por isso, poucos versos escreveu enquanto lá esteve. De fato, há nesses tempos um silêncio em termos de poesia escrita. Os poemas sobre Timor são do final dos anos 60 , quando já não está nem espera que lhe autorizem voltar tão cedo ao território. São memória.

DDB - Mas são todos escritos a posteriori ou ele escreve também durante a sua estadia?

PS - Durante as estadas em Timor o que escreve são despachos, relatórios e cartas. Cinatti diz, a certa altura, que já não precisa de escrever um diário porque as cartas aos amigos são o seu diário. $\mathrm{Na}$ verdade, ele 
guarda cópias dessas cartas - um recurso precioso, pois seria muito difícil recolhê-las hoje dos destinatários. Assim, temos hoje um registo, se não diário pelo menos semanal, de alguns dos anos em que Cinatti esteve em Timor. Algumas lhe terão servido de apoio quando, de memória, escreve poemas que evocam as suas experiências no território. Pelo menos, foram encontradas recolhidas num único dossier com aspeto de terem sido manuseadas.

DDB - E quem são os destinatários?

PS - São amigos com quem convivia em Portugal. Uma longa lista. Nalguns casos, como as duas ou três cartas a Ruben A, Cinatti adota um estilo jocoso, por vezes surrealista. Terão interesse literário, mas pouca informação biográfica. Outras dão notícia de viagens dentro ou fora do território, ou de acontecimentos que Cinatti presenciou. Notas e relatórios de serviço também se encontram no espólio, assim como uma recolha interessante de trabalhos preparados por administrativos para a progressão na carreira, com dados e costumes das povoações.

DDB - Era uma das perguntas que eu lhe queria fazer. Já temos uma descrição do espólio?

PS - A Fundação Macau subsidiou um projeto em que me empenhava há muitos anos. Permitiu contratar uma empresa especializada na organização de espólios que já apresentou uma descrição detalhada do espólio recolhido na Biblioteca João Paulo II, da Universidade Católica Portuguesa.

DDB - A primeira organização foi sua, não foi?

PS - A primeira organização foi minha. Nalguns casos, tratou-se de salvar documentos que estavam prestes a desaparecer. Foi em casa do próprio Ruy, onde cheguei algumas semanas depois da sua morte. Já tinha sido tirado tudo que parecia ter valor, incluindo os livros e os quadros. A casa estava vazia, exceto um monte de "lixo" no meio da sala e um pequeno quarto esconso, na inclinação do telhado, cheio de pequenas caixas de papelão para as quais tinham sido atirados e remexidos pelo Ruy cadernos de apontamentos, folhas soltas com poemas, recibos, bilhetes... Aí estava também um conjunto de pequenos dossiês que se 
revelaram livros de poesia dactilografados, prontos para publicação. No espólio, representam cerca de um metro de prateleira de livros de poesia inéditos - o que é impressionante.

DDB - Portanto, aqueles que o professor publicou na Presença eram apenas uma amostra disso?

PS - Esses estavam mesmo preparados para a tipografia. Eram os que me pareciam em melhores condições para publicação. Depois havia folhas de poemas policopiados [xerocados] que o Ruy, nos anos 70 e 80 distribuía pelas ruas da cidade. Se tiver acesso a esses papeis, há-de ver que muitos dos poemas trazem indicação de pertença a um livro. Mas os nomes desses livros não coincidem com os dos dossiês que atrás referi.

DDB - Sei que está a preparar uma nova edição da poesia de Cinatti...

PS - Essa edição não é da minha responsabilidade, é da editora Assírio \& Alvim, preparada por Luís Manuel Gaspar e com prefácio de Joana Matos Frias. Retoma e completa a edição publicada pela Imprensa Nacional no final dos anos 80 . Penso que recolherá só os livros de poesia editados em vida. No meu projeto, está prevista a publicação de dois volumes de dispersos, organizados por Vasco Rosa. O primeiro recolhe textos anteriores a 1948. O segundo, textos referentes ao Oriente, incluindo os de cariz científico.

DDB - A relação dele com o colonialismo português é uma das razões pelas quais o Cinatti caiu um pouco no olvido, não é?

PS - Penso que são vários os motivos de um certo esquecimento. Em primeiro lugar, Cinatti não pertenceu verdadeiramente a nenhuma corrente literária. Não entra nem na tradição dos presencistas, nem do Neorrealismo. Pertence ao grupo dos Cadernos de Poesia, que é bastante díspar. Por outro lado, reflete alguma herança da poesia anglo-saxónica, o que não era comum na literatura de língua portuguesa - Fernando Pessoa à parte. Normal, nessa altura, era a influência francesa e, eventualmente, de língua espanhola. $\mathrm{O}$ grupo de Cinatti inclui vários jovens da área das ciências, como Jorge de Sena ou o José Blanc de Portugal, para quem o inglês é acessível. Cinatti também é da área das ciências, mas com a motivação de ter nascido em Londres e a vantagem de ter aprendido inglês em criança. 
DDB - Ele era bilíngue?

PS - Não seria propriamente bilíngue. Era fluente em inglês e escrevia quase sem falhas. Apesar disso, pedia ao meu pai para rever os textos de responsabilidade que escrevia em inglês. Mas lia com gosto e comentava literatura em língua inglesa.

PS - ... depois há o fato de ser católico - e assumidamente católico -, o que não esteve propriamente na moda nos meios literários portugueses. Acrescente-se a sua ligação à administração colonial, quando a opinião dominante de ambos os lados da Guerra Fria é que as colónias estão condenadas a desaparecer, ou nunca deviam ter existido. Cinatti, pelo contrário, acredita no que pode e deve fazer nas colónias portuguesas. Vive mesmo horas do desânimo, ao ver que a administração em Timor trava, na prática, o potencial que o território teria para desenvolver uma nova cultura, espécie de fusão das culturas portuguesa e local. Fala já disso, quando começa a refletir sobre o desenvolvimento sustentável de Timor, nos anos 50; e aprofunda a ideia quando estuda nas culturas nativas o saber empírico de séculos sobre como conviver com a natureza local na agricultura, na administração e na arquitetura. Duas viagens consolidam o seu sonho. Ao passar pelo Irão, em1965, visita Persépolis, e aí se espanta com a sabedoria dos antigos persas, que souberam integrar os povos do Médio Oriente num estilo de regime constitucional assente no respeito pelas culturas e religiões locais. Um ano mais tarde, passa pelo México, no regresso da sua última visita a Timor. A fusão que observa da cultura ibérica com as culturas azteca e maia deixa-o entusiasmadíssimo. $\mathrm{O}$ impacto é evidente em Manhã imensa.

DDB - Dá a ideia de ele ser uma pessoa muito entusiasmada...

PS - Era uma pessoa com grandes picos de atividade criativa, seguidos de quebras profundas. Há momentos em que caminha, viaja, parte ao encontro de coisas novas, observa minuciosamente o que se passa à volta. Talvez por isso, é um homem de pontes - espírito "ecuménico" que associa ao seu catolicismo. Dá-se bem tanto com gente do Partido Comunista, como da oposição democrática e do regime de Salazar. Mas no final dos anos 60, é-lhe evidente que o regime se esgotou. Nas eleições de 69, em que o Marcelo Caetano é eleito, vota na oposição, por considerar que o regime está caduco. 
DDB - Mas é curioso ver que a poesia dele vai muito além do que seria uma poesia colonial. É uma poesia até contrária, porque dá uma voz muito forte ao outro.

PS - Recentemente, tive disso uma experiência muito viva. Convidaramme para ir a Díli, em Julho de 2015, falar sobre Ruy Cinatti. Visitei e fiz uma das minhas palestras no Museu da Resistência, porque lá se encontra a obra do Ruy. Como escrevi no Jornal de Letras, devem ser poucos os membros da administração portuguesa celebrados como heróis da resistência na colônia que ajudaram a administrar. A realidade é que, em Timor, os livros de Cinatti são lidos e pedem-se novas edições. Isto é tão mais curioso quanto, depois da revolução de Abril de 1974, ele se ofereceu para seguir como conselheiro da administração nova, incumbida de descolonizar Timor, e respondem-lhe que não, que não é preciso. Deviam achar que era um poeta sonhador e incontrolável. Chegou a escrever uma carta para o Diário de Notícias - que não é publicada - a avisar que, seguindo os caminhos que tinham sido adotados, o processo não correria bem e a Indonésia aproveitaria para invadir. Meses mais tarde, dá uma longa entrevista ao semanário católico Nova Terra, em que volta a chamar a atenção para o risco de reavivar as tradicionais rivalidades entre etnias. No nevoeiro ideológico que predominava, o aviso feito de conhecimento da realidade simplesmente passou despercebido.

DDB - Como é que avalia o lugar do Cinatti na poesia portuguesa?

PS - Dizem-me que ele é lido e apreciado pela geração mais nova. Já o era pela geração de Joaquim Manuel Magalhães, agora é-o pela de Manuel de Freitas. Talvez seja pela forma direta, quase descritiva com que a poesia de Cinatti aborda a realidade. Joana Matos Frias, se não me engano, fala da sua escrita por vezes quase cinematográfica. Não fica pela superfície. Olha as coisas como são, com a objetividade que Cinatti tanto aprecia na ciência, mas ao mesmo tempo procura nelas uma dimensão de profundidade; ou talvez de transcendência - palavra que uso com alguma hesitação, porque nem sempre bem entendida. Encontro um certo paralelo com a cultura bíblica, sempre atenta à multifacetada condição humana de que dá notícia não pela filosofia mas pela subtileza da linguagem em grande parte narrativa; e depois os pequenos jogos de palavras, a metáfora bem escolhida que rasga a opacidade do acontecimento e abre para horizontes inesperados de humanidade. E, no limite - ou na recusa do limite -, a presença incontornável do divino. 
DDB - E a poesia do Cinatti faria algo de semelhante?

PS - Tenho a impressão que sim. É claro que há na sua obra uma dimensão de fé. Mas não é uma poesia de sacristia. É uma poesia em que ciência e fé o mergulham e amarram ao quotidiano. É uma vida que tem sempre algo de espanto e encantamento com a realidade. Por exemplo, ser capaz de se espantar com uns gregos que, à refeição, partem os pratos num restaurante de Lisboa - está num dos poemas policopiados recolhidos em antologia por Manuel de Freitas. Não é fácil para o leitor. Confesso que, inicialmente não apreciava a sua poesia. Ele dava-me os livros mas não me prendiam a atenção. Depois, por causa da tese de doutoramento, fui aprendendo a gostar...

DDB - Este ano foi o do centenário do poeta. Gostaria que nos falasse sobre o que aconteceu e o que está previsto.

PS - O poeta Manuel de Freitas publicou duas obras, uma antologia da poesia de Cinatti em geral e uma antologia das folhas policopiadas, com um excelente posfácio. Em Macau, tivemos um simpósio com um pequeno número de professores universitários, seguido de um evento público. A Casa Pessoa promoveu um colóquio. Na Universidade Católica, acondicionou-se e concluiu-se a organização do espólio, e vamos entrar numa fase de a tornar acessível de forma digital, com a possibilidade das pessoas poderem interagir com alguns textos de forma virtual. Em Timor, houve três conferências sobre Cinatti e uma visita à Escola Portuguesa Ruy Cinatti, em Díli - os alunos fizeram um belo desenho de Cinatti na parede de entrada. Quando se vem de Portugal, onde o Cinatti é mais ou menos esquecido do grande público, e se descobre que o impacto da sua personalidade é assim tão grande em Timor, há a sensação de que isto lhe teria agradado sobremaneira. Depois, vão celebrar, em junho ou julho de 2016, os 50 anos da chegada do Ruy a Timor. Temos ainda a criação de um website dedicado à obra de Ruy Cinatti, que Vasco Rosa está a organizar. Por coincidência, em outubro completam-se os 30 anos da sua morte. Talvez esta combinação de aniversários possa contribuir para que o nome e a obra de Cinatti alcancem o relevo que merecem, como expressão desse encontro fraterno de povos e culturas que caracteriza o mundo da lusofonia. 